American Journal Immunology 2(4): 77-87, 2006

ISSN 1553-619X

(C) 2006 Science Publications

\title{
Immunological Evidence for Peptide-Carbohydrate Mimicry with a Group A Streptococcus Polysaccharide-Mimetic Peptide
}

\author{
Silvia Borrelli, Rehana B. Hossany, Susan Findlay and B. Mario Pinto \\ Department of Chemistry, Simon Fraser University, Burnaby, B.C., Canada V5A 1S6
}

\begin{abstract}
The immunogenicity of a peptide-protein conjugate developed by linking a peptide mimic DRPVPY of the Group A Streptococcus cell-wall polysaccharide (GAS-CWPS), to tetanus toxoid (TT) was examined. BALB/c mice were immunized three times subcutaneously following homologous or heterologous prime/boost strategies at 4- or 6- week intervals in two different experiments. DRPVPY-TT, CWPS-TT, heat-killed, pepsin-treated GAS bacteria (with exposed polysaccharide) and TT, were used as immunogens with alum as adjuvant. Antibody titers were determined by ELISA with GAS bacteria (with exposed polysaccharide) and DRPVPY-linked to bovine serum albumin (BSA, DRPVPY-BSA) as solid phase antigens. All mice primed with DRPVPY-TT developed high IgG antipeptide and anti-GAS titers. The binding of polyclonal anti-peptide antibodies to GAS could be inhibited by purified CWPS, synthetic oligosaccharides corresponding to CWPS, DRPVPY-BSA, DRPVPY and DRPVP, as assessed by competitive-inhibition ELISA. Anti-oligosaccharide titers were also obtained upon titration of anti-peptide sera with synthetic oligosaccharide-BSA conjugates. All mice primed with CWPS-TT and mice primed and boosted with GAS developed IgG anti-peptide titers. These data demonstrate conclusively the cross-reactivity of the immune responses and support the hypothesis of antigenic mimicry of the GAS-CWPS by the hexapeptide DRPVPY. However, mice boosted with DRPVPY-TT, after 6-8 weeks, showed a decrease in IgG anti-GAS titers, but an increase in IgG anti-peptide titers, suggesting carrier-induced suppression of the response to polysaccharide. Strategies are outlined for further refinement of a DRPVPY conjugate as a surrogate of the cell-wall polysaccharide for use in vaccines against Group A Streptococcus.
\end{abstract}

Key words: Group A Streptococcus, cell-wall polysaccharide, mimetic-peptide, immunology

\section{INTRODUCTION}

Streptococcus pyogenes (Group A Streptococcus, GAS) is a gram-positive extracellular bacterium, which colonizes the throat or skin and is responsible for a number of suppurative infections and their nonsuppurative, immunologically-mediated sequelae including acute rheumatic fever, acute glomerolunephritis and reactive arthritis ${ }^{[1]}$. GAS has been recognized as a common cause of bacterial pharyngitis (strep throat), skin abscesses, impetigo and scarlet fever. More recently, GAS has been recognized as the causative agent of toxic shock-like syndrome and necrotizing fasciitis which invades skin and soft tissues and in severe cases leaves infected tissues destroyed ${ }^{[1-4]}$. Acute rheumatic fever and rheumatic heart disease are the most serious autoimmune sequelae of GAS infection affecting children worldwide. After the advent of antibiotics, diseases caused by S. pyogenes declined in incidence and severity in developed countries ${ }^{[5]}$. In the last 20 years, these diseases have re-emerged in industrial countries and a dramatic increase of their frequency is observed in developing countries ${ }^{[6,7]}$. Mass vaccination would therefore be of interest for efficient prevention of these infections ${ }^{[1,8]}$.
The Lancefield classification scheme of serologic typing distinguished the beta-hemolytic Streptococci based on their Group A cell-wall polysaccharide (CWPS), composed of $N$-acetylglucosamine linked to a rhamnose polymer backbone (compound 1, Fig. 1). Streptococci were also serologically separated into M protein serotypes based on a surface protein. More than $80 \mathrm{M}$ protein serotypes have been identified. Vaccines containing the streptococcal $\mathrm{M}$ protein and its component peptides ${ }^{[9-11]}$ as well as CWPS-protein conjugates $^{[12,13]}$ are under investigation, among other antigen ${ }^{[1,14]}$. The validity of the CWPS as a viable vaccine candidate has been established in a recent study $^{[13]}$.

An alternative approach to vaccine design is the use of molecules that mimic the immunogenic element of interest ${ }^{[15,16]}$. Carbohydrate-mimetic peptides have potential as surrogate ligands for traditional carbohydrates vaccines providing more discriminating immune responses ${ }^{[15]}$. Screening of phage-displayed peptide libraries with carbohydrate-specific antibodies had identified carbohydrate-mimetic peptides with demonstrated antigenic and immunogenic potential in certain cases $^{[15,17-19]}$. In the present context, a GAS carbohydrate -mimetic peptide,

Corresponding Author: Silvia Borrelli, Department of Chemistry, Simon Fraser University, Burnaby, B.C., Canada V5A 1S6 


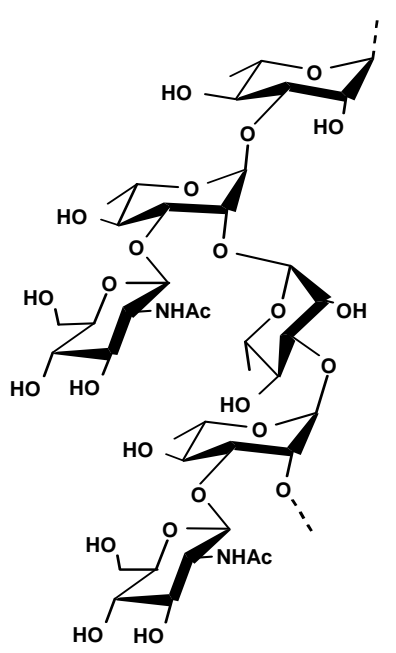

1

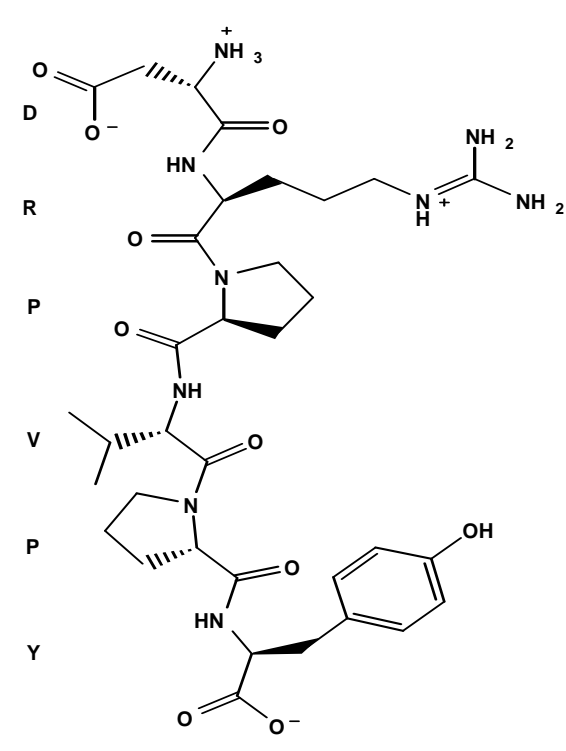

2

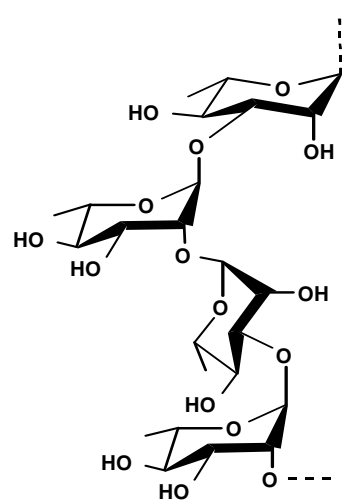

3

Fig. 1: Cell-wall polysaccharide (CWPS) of the bacteria Streptococcus Group A (compound 1), CWPS-peptide mimic: DRPVPY (compound 2) and CWPS variant (CWPSv, compound 3)

DRPVPY (compound 2, Fig. 1), cross-reactive with an anti-CWPS monoclonal antibody, SA-3, was identified $^{[20]}$. SA-3 recognizes a branched trisaccharide repeating unit L-Rha- $\alpha-(1 \rightarrow 2)-[D-G l c N A c-\beta-(1 \rightarrow 3)]-$ $\alpha$-L-Rha as an epitope ${ }^{[21]}$. Detailed immunochemical studies of the recognition of DRPVPY by SA-3 showed that the mechanism of peptide binding differs from that of the carbohydrate ${ }^{[20]}$. The structure of this peptide is worthy of comment. The presence of two prolines adds defined structure to this short peptide. A detailed transferred-NOE NMR study of the antibody-bound conformation of the peptide has been described in detail by Johnson et al. ${ }^{[22,23]}$.

It was clear that a defined tight turn conformation in the VPY region, a likely peptide epitope, is recognized by the SA-3 antibody used to isolate this peptide in the original phage screening protocol. Evidence was presented that this conformation was also present in the ensemble of conformations of the free peptide. STD-NMR experiments also indicated that the $\mathrm{D}$ residue did not form contacts within the antibody combining site, a results that is consistent with previous immunochemical studies in which the $D$ residue was modified $^{[24]}$. These data, taken together, augur well for a presentation of this peptide conformation on the phage surface. The synthesis of DRPVPY-based conjugates, to bovine serum albumin, BSA (compound 4, Fig. 2) and to tetanus toxoid, TT, (compound 5, Fig. 2) together with their immunochemical evaluation with SA-3 was reported recently ${ }^{[24]}$. It is noteworthy that a search of the human genome reveals that the sequence DRPVPY is not present (NCBI's protein database).
We report herein, the immunogenicity of a DRPVPY-TT conjugate (compound 5, Fig. 2) in $\mathrm{BALB} / \mathrm{c}$ mice, the cross-reactivity of the anti-peptide sera with CWPS and the characterization of the specificity of the antibody response observed by competitive-inhibition ELISA. The potential of the conjugate as a surrogate compound in vaccines against GAS and new insights into carbohydrate-peptide antigenic mimicry are presented.

\section{MATERIALS AND METHODS}

Group A Streptococcus (GAS) used as solid-phase antigen for ELISA and as immunogen in control mice groups: Streptococcus pyogenes Group A type 4, strain J17A4 bacteria were heat-killed and pepsin-digested to expose the cell-wall polysaccharide, as described ${ }^{[21,25]}$; kindly provided by Pitner ${ }^{[26]}$. The original treatment with pepsin was reported by Krause et $a l^{[25]}$, to remove most of protein and expose the cellwall carbohydrate antigens. Immunization with such bacteria in several studies in the past ${ }^{[21,25,26]}$ has shown that a strong anti-polysaccharide response is obtained.

Preparation of Group A polysaccharide and Group A variant polysaccharide used as inhibitors and CWPS-TT conjugate: The cell-wall Group A polysaccharide (CWPS, compound 1, Fig. 1) and its variant (CWPSv, compound 3, Fig. 1) form were extracted and characterized as described ${ }^{[12]}$. The CWPS-TT conjugate was obtained by reductive amination using cyanoborohydride as described ${ }^{[12]}$. 


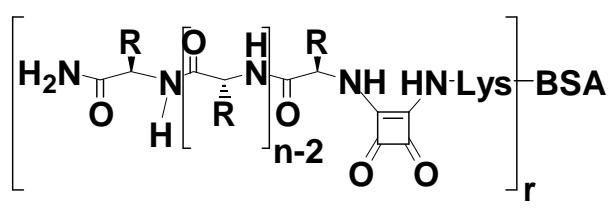

$\begin{array}{lll}n & \text { peptide hapten } & r \\ 6 & \text { DRPVPY } & 28\end{array}$

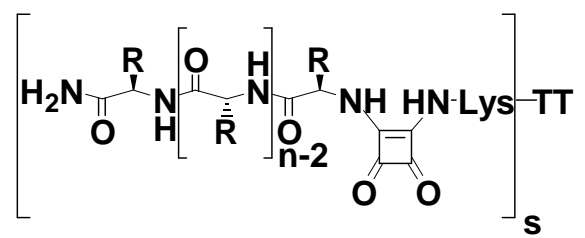

n peptide hapten $\mathbf{s}$

6 DRPVPY
39

Fig. 2: Synthetic peptide conjugates: DRPVPY-BSA (compound 4, left) and DRPVPY-TT (compound 5, right) used in this study

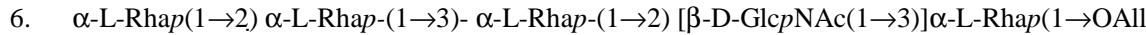

7. $\alpha$-L-Rhap- $(1 \rightarrow 2)[\beta-\mathrm{D}-\mathrm{Glc} p \mathrm{NAc}(1 \rightarrow 3)]-\alpha$-L-Rha $(1 \rightarrow \mathrm{OAll}$

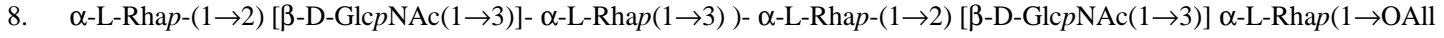

9. CWPS-BSA

10. $\quad\left[-\alpha \text {-L-Rhap- }(1 \rightarrow 2)[\beta-\mathrm{D}-\mathrm{Glc} p \mathrm{NAc}(1 \rightarrow 3)]-\alpha-\mathrm{L}-\mathrm{Rha} p-\mathrm{O}\left(\mathrm{CH}_{2}\right)_{8} \mathrm{CONH}\right]_{8-18}-\mathrm{BSA}$

11. $\left[[\beta-\mathrm{D}-\mathrm{Glc} p \mathrm{NAc}(1 \rightarrow 3)]-\alpha \text {-L-Rhap- }(1 \rightarrow 3)-\alpha \text {-L-Rhap- }(1 \rightarrow 2)[\beta-\mathrm{D}-\mathrm{Glc} p \mathrm{NAc}(1 \rightarrow 3)]-\alpha-\mathrm{L}-\mathrm{Rhap}-\mathrm{O}\left(\mathrm{CH}_{2}\right)_{8} \mathrm{CONH}\right]_{8-18}-\mathrm{BSA}$

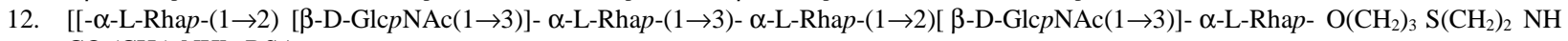
$\left.\mathrm{CO}\left(\mathrm{CH}_{2}\right)_{2} \mathrm{NH}\right]_{5}-\mathrm{BSA}$

13. $\left[\left[-\alpha-L-R h a p-(1 \rightarrow 2) \quad[\beta-D-G l c p N A c(1 \rightarrow 3)]-\alpha-L-R h a p-(1 \rightarrow 3)-\alpha-L-R h a p-(1 \rightarrow 2)[\beta-D-G l c p N A c(1 \rightarrow 3)]-\alpha-L-R^{2} a p-O\left(C_{2}\right)_{3} S\left(\mathrm{CH}_{2}\right)_{2} N H-\right.\right.$ squarate ${ }_{16}$-BSA

Fig. 3: Structures of synthetic oligosaccharide inhibitors and glycoconjugates: pentasaccharide (compound 6), branched-trisaccharide (compound 7) and hexasaccharide (compound 8), a polysaccharide BSA-conjugate (compound 9) and other oligosaccharide protein conjugates (compounds 10-13) used as solid-phase antigens in titration ELISA

These compounds were kindly provided by Dr. Francis Michon (Baxter Vaccines, MD, USA).

Monoclonal Antibody MAb SA3, peptides DRPVPY and DRPVP, DRPVPY-TT and DRPVPY-BSA conjugates: The MAb SA3 (IgM) has been described earlier $^{[21]}$ and was used as an ELISA control after purification from ascites fluid by gel-filtration chromatography. The CWPS-peptide mimetic DRPVPY was synthesized using the Fmoc solid-phase strategy and linked via the amino terminus to a bifunctional linker, diethylsquarate and then conjugated to tetanus toxoid (TT) or bovine serum albumin (BSA) as immunogenic carriers, as described ${ }^{[24]}$ (compounds 4 and 5, Fig. 2). The average level of incorporation of the peptide on TT was $65 \%$ while that on BSA was $100 \%$ (Fig. 2). The peptide DRPVP was also synthesized as described above and evaluated as an inhibitor in competitive inhibition ELISA assays.

Synthetic oligosaccharides and glycoconjugates used as inhibitors and solid-phase antigens in ELISA: The pentasaccharide (compound 6, Fig. 3), the branchedtrisaccharide (compound 7, Fig. 3) and hexasaccharide (compound 8, Fig. 3) were available from our previous work $^{[27,28]}$, CWPS-BSA (compound 9, Fig. 3), branched-trisaccharide-BSA (compound 10, Fig. 3), pentasaccharide-BSA (compound 11, Fig. 3), (hexasaccharide) 5 -BSA (compound 12, Fig. 3), (hexasaccharide) ${ }_{16}$-squarate-BSA (compound 13, Fig. 3 ) were also available from our previous work ${ }^{[21,29]}$.
Experimental groups of mice and immunization protocols: Female BALB/c mice (6-8 weeks) were obtained from Charles River Breeding Laboratories, (Montreal, Quebec, Canada) and were maintained in our Animal Facility following the animal care guidelines. Five groups of 4 mice each were injected subcutaneously (s.c.) in week 0,4 and 10, with the conjugates, Alhydrogel (2\%, Superfos Brenntag Biosector, Frederikssund, Denmark), or controls in two different experimental protocols. Mice were bled every 2 weeks, their sera analyzed and mean reciprocal endpoint titers and standard deviation determined.

In experiment 1 , Control groups received $100 \mu \mathrm{l}$ of heat-killed pepsin-treated GAS bacteria (Group 5, G5) or $100 \mu \mathrm{g}$ of Alhydrogel and $100 \mu \mathrm{g}$ of TT (Group 4, G4), in weeks 0, 4 and 10. Mice from Group 1 (G1) received $100 \mu \mathrm{g}$ Alhydrogel and $100 \mu \mathrm{g}$ of DRPVPYTT, in weeks 0 and 4. Results obtained in weeks 6 and 8 lead to boost these mice with $50 \mu \mathrm{g}$ DRPVPY-BSA in week 10 .

In Groups 2 (G2) and 3 (G3) a heterologous prime/boost strategy was implemented. Group 2 mice were primed with $1 \mu \mathrm{g}$ CWPS-TT and boosted with 100 $\mu \mathrm{g}$ DRPVPY-TT in week 4 and results led us to boost with $50 \mu \mathrm{g}$ of DRPVPY-BSA in week 10. Group 3 mice were primed with $100 \mu \mathrm{g}$ DRPVPY-TT and boosted with $1 \mu \mathrm{g}$ CWPS-TT in week 4 and results led to a final boost with $50 \mu \mathrm{g}$ of DRPVPY-TT in week 10. 
In experiment 2 , Control groups received $100 \mu \mathrm{g}$ of Alhydrogel and $2 \mathrm{mg}$ of CWPS-TT (Group 4, G4) or $100 \mu \mathrm{g}$ of TT (Group 5, G5) in weeks 0, 4 and 10. Mice from Group 1 (G1) received $100 \mu \mathrm{g}$ DRPVPY-TT, once and were then euthanized in week 5 . Group 2 (G2) mice were immunized with $100 \mathrm{mg}$ DRPVPY-TT in weeks 1 and 4. Results from these weeks led us to give a final boost with $2 \mu \mathrm{g}$ CWPS-TT in week 10 . Mice from Group 3 (G3) were primed with $2 \mu \mathrm{g}$ CWPS-TT and boosted with $100 \mu \mathrm{g}$ DRPVPY-TT in week 4 and results led to a final boost was with $10 \mu \mathrm{g}$ DRPVPY-TT in week 10.

ELISA for binding antibody: Antibody titers to DRPVPY and GAS polysaccharide in sera from vaccinated mice were determined before vaccination and 2 weeks after each vaccination by ELISA, as described $^{[30]}$. ELISAs were performed in 96-well plates (NUNC-MaxiSorp, Rochester, NY), coated overnight with $100 \mu \mathrm{l} /$ well of DRPVPY-BSA (or TT, $10 \mu \mathrm{g}$ $\mathrm{mL}^{-1}$ ) or with a suspension of heat-killed, pepsintreated GAS bacteria corresponding to $\mathrm{A}_{595 \mathrm{~nm}} \sim 0.25$. Wells were blocked by the addition of $1 \%$ BSA for $2 \mathrm{~h}$ at room temperature. The plates were washed three times with a washing solution of $0.05 \%$ Tween 20 and $0.9 \% \mathrm{NaCl}$. Antisera, 3-fold-serially diluted in $0.05 \%$ Tween PBS (PBS-T) at a starting dilution of $1 / 50$, were added (100 $\mu \mathrm{l}$ per well) and incubated for $3 \mathrm{~h}$ at room temperature. After washing four times as before, followed by the addition of $100 \mu \mathrm{l}$ per well of alkaline phosphatase-labeled goat anti-mouse $\operatorname{IgG}$ or $\operatorname{IgM}$ (Caltag Laboratories, San Francisco, CA) diluted 1:3000 in PBS-T. The plates were incubated overnight at room temperature and again washed four times. 100 $\mu \mathrm{l}$ of substrate solution containing p-nitrophenyl phosphate $\left(1 \mathrm{mg} \mathrm{mL} \mathrm{mL}^{-1}\right.$, Kirkegaard \& Perry lab, Gaithersburg, MD) was added to the wells. After 10 to $60 \mathrm{~min}$ at room temperature, the plates were scanned at $405 \mathrm{~nm}$ in a SpectraMax 340 microplate reader. The titer was defined as the highest dilution yielding an absorbance $\geq 0.1$ after subtracting twice the average background reading. The negative control consisted of wells without serum. The positive control was the mouse MAb SA-3, appropriately diluted.

Competitive-inhibition ELISA studies with CWPS, CWPSv, DRPVPY, DRPVP, DRPVPY-BSA and synthetic oligosaccharides corresponding to CWPS as inhibitors: Sera from those mice that had the highest anti-DRPVPY antibody titers cross-reactive to GAS bacteria in week 4 (G1-experiment 2), were used. Sera were incubated in duplicate at a final dilution of 1:100 with two-fold serial dilutions of inhibitors (compounds 1-3, Fig. 1; compound 4, Fig. 2, compounds 6-8, Fig. 3) in PBS-T, starting at an initial concentration of $500 \mu \mathrm{g}$ $\mathrm{mL}^{-1}$, for $1 \mathrm{~h}$ at room temperature. Then, $100 \mu \mathrm{l}$ of the mixtures were transferred to plates coated with antigens and incubated at room temperature for $3 \mathrm{~h}$. The plates were washed and the bound $\operatorname{IgG}$ was detected as described for the ELISA above.

Titration ELISA: Microtiter plates (NUNC) were coated overnight at room temperature with CWPS-BSA (compound 9, Fig. 3), branched-trisaccharide-BSA (compound 10, Fig. 3), pentasaccharide-BSA (compound 11, Fig. 3), (hexasaccharide) - $_{5}$ BSA (compound 12, Fig. 3) and (hexasaccharide-squarate) 16- $^{-}$ BSA (compound 13, Fig. 3) conjugates $\left(10 \mu \mathrm{g} \mathrm{mL}^{-1}\right)$, diluted in PBS ( $\mathrm{pH}=7.4)$. Plates were blocked with 100 $\mu \mathrm{l} /$ well of $1 \%$ BSA in PBS for $2 \mathrm{~h}$ at room temperature.

Mouse antisera were serially diluted (starting dilution of 1/50) in PBS-T and duplicate aliquots (100 $\mu \mathrm{l} /$ well) were added to coated microtiter plates and incubated for $3 \mathrm{~h}$ at room temperature. The ELISA was performed as described above.

\section{RESULTS}

Immunogenicity of the peptide conjugates: Antibody titers to DRPVPY: The individual mouse antisera (4 mice per group, 5 groups of mice: G1 to G5) were evaluated for the relative amounts of $\operatorname{IgG}$ antibody they contained that bound to DRPVPY-BSA. Pre-immune sera screened by ELISA, using DRPVPY-BSA as solid phase antigen, showed low background activity (week 0 , Fig. 4 A-B). Mice primed with $100 \mu \mathrm{g}$ of the DRPVPY-TT conjugate responded with high IgG antibody titers against DRPVPY-BSA (weeks 2 and 4, Fig. 4 A-B). Increases were seen after boosting mice from G1-experiment 1 (Fig. 4A) and G2-experiment 2 (Fig. 4B) in weeks 6 and 8. Control groups (G4 and G5) showed much lower mean end-point titers to peptide at all time points. This result indicates that the conjugates effectively promoted a strong and rapid thymusdependent response to DRPVPY.

Cross-reactivity: Anti-peptide antibodies bind to exposed-polysaccharide on Group A Streptococcus (GAS) bacteria Titers against exposed polysaccharide on GAS bacteria were obtained when a high dose of the peptide-experimental vaccine was administered to mice (Fig. 5-6). A lower dose of 20-40 $\mu \mathrm{g} /$ mouse did not elicit high cross-reactive titers (data not shown). The subcutaneous immunization with DRPVPY-TT $(100 \mu \mathrm{g}$ $\mathrm{mL}^{-1}$ ) of mice resulted in anti-GAS primary responses (IgM and IgG, weeks 2 and 4, Fig. 5-6). The response was higher for $\operatorname{IgG}$ than for IgM. Four weeks after priming, the $\operatorname{IgG}$ response was higher than that at week 2. The IgM response declined four weeks after priming (Fig. 5-6). No titer increases against TT, used as control, were seen. These anti-GAS titers, were much lower than those against peptide.

A lack of secondary response (IgG) cross-reactive with GAS bacteria was observed after mice received a booster injection of DRPVPY-TT at equal dose (G1 
experiment 1 and $\mathrm{G} 2$ experiment 2, respectively, in week 6-8, Fig. 5-6) or lower (G3 experiment 2, at week 12, Fig. 6). Attempts to save the cross-reactive response were conducted in week 10 in both experiments. The immunization carrier was changed to BSA and boosting with a lower dose of DRPVPY-BSA were not successful (G1 experiment 1, week 12, Fig. 5). A booster injection with a 10-fold lower dose of DRPVPY-TT was tried in G3 experiment 2, week 10, or half dose (G3-experiment 1, week 10); however, a secondary-like response (fast, strong and high $\mathrm{IgG}$ titers) was not observed at week 12 (Fig. 5 and 6).

Heterologous boosting strategies: Priming with DRPVPY-TT and boosting with CWPS-TT (G3 experiment 1-Fig. 5) resulted in no titer increases against GAS (Fig. 5-G3, week 6). Priming with CWPSTT and boosting with DRPVPY-TT at a high (Fig. 5G2 experiment 1, week 6) and at a lower dose (Fig. 6G3 experiment 2, week 10-12) or even using another carrier, BSA (Fig. 5-G2 experiment 1, week 10-12), although titers against GAS increased (Fig. 5-G2-week 8 and Fig.6-G3-week 8), did not have a response with the characteristics of a secondary response .

Specificity of the primary response to DRPVPY-TT: To investigate the epitope specificities of the antiDRPVPY polyclonal antibodies, competitive ELISA inhibitions were performed. The antisera with highest endpoint-titers, obtained at week 5 of mice from G1experiment 2, immunized once with DRPVPY-TT were used in these experiments. Titration experiments of antisera were performed for each experiment and the dilution used corresponded to an $\mathrm{A}_{405 \mathrm{~nm}} \sim 1$, after 20 min. Heat-killed, pepsin-treated Group A Streptococcus (GAS) was used as the solid-phase antigen.

Competitive inhibition ELISA with CWPS and CWPSv were performed with GAS bacteria as the solid-phase antigen. Only the native CWPS inhibited the binding of the anti-DRPVPY polyclonal antibodies (IgG, Fig. 7 I), with greatest inhibitory activity of about $30 \%$ at a concentration of $250 \mu \mathrm{g} \mathrm{mL}^{-1}$. No inhibition curve was obtained with the CWPSv under the same conditions. These data confirm the binding of the antipeptide polyclonal antibodies with GAS and confirm that the GlcNAc moiety, the immunodominant sugar, is a critical part of the GAS-CWPS epitope.

Inhibition ELISA studies with DRPVPY, DRPVP and DRPVPY-BSA-conjugate as inhibitors of the binding of anti-DRPVPY polyclonal antibodies to GAS bacteria showed that the DRPVPY-BSA conjugate was the best inhibitor, reaching the maximum inhibitory activity, about $70 \%$, at a concentration of $100 \mu \mathrm{g} \mathrm{mL}^{-1}$. DRPVPY and DRPVP showed 35 and 27\% inhibition, respectively and at the same concentration (Fig. 7II).
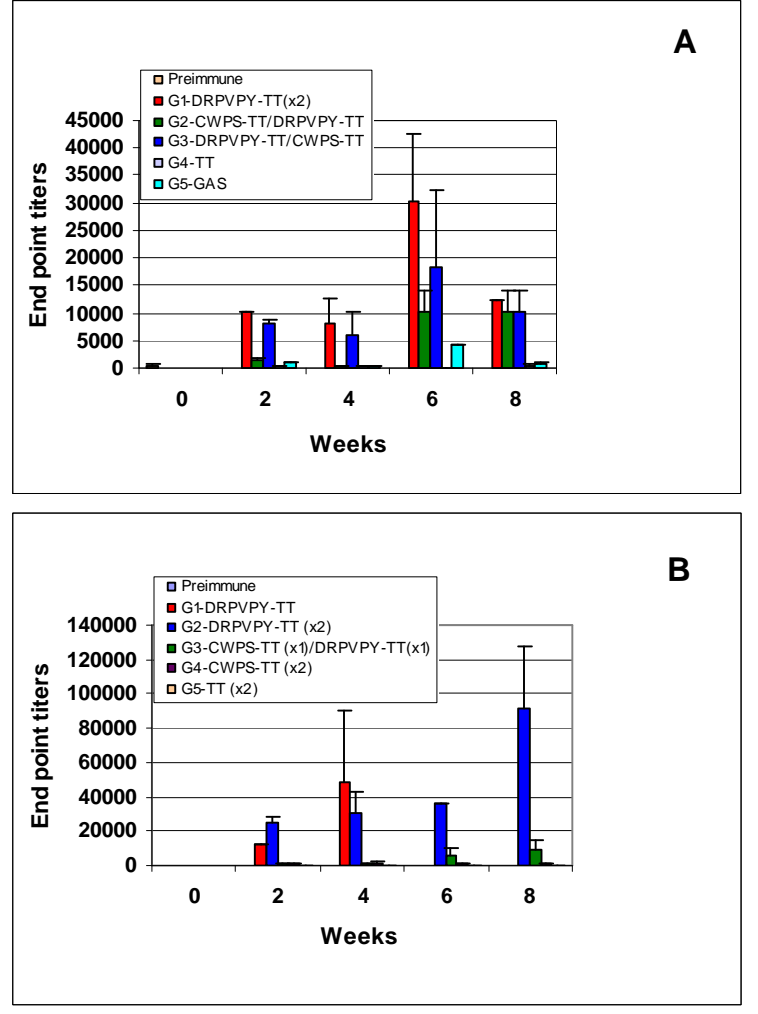

Fig. 4: Immunogenicity of the peptide conjugates: Antibodies titers (IgG) to DRPVPY. Experiment 1 (A), Experiment 2 (B). Plates were coated with DRPVPY-BSA (compound 4, Fig. $2,10 \mu \mathrm{g} / \mathrm{ml}$ ) as described in Materials and Methods

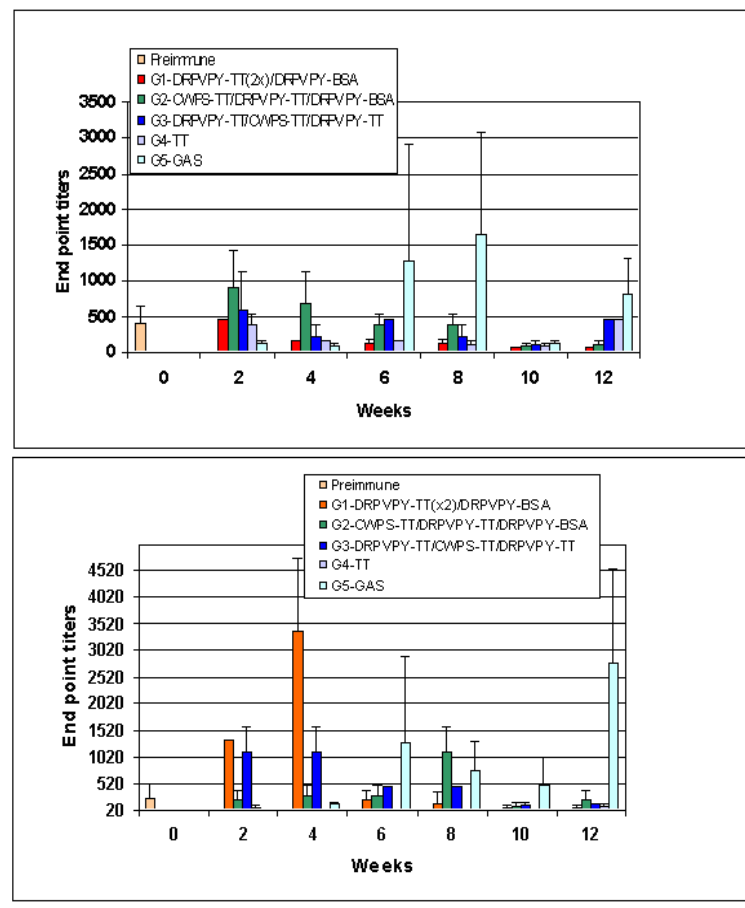

Fig. 5: Cross-reactivity in Experiment 1: Anti-peptide antibodies binding to heat-killed, pepsin treated Group A Streptococcus (GAS) bacteria as the solid-phase antigen in ELISA (see Materials and Methods). IgM response (top) and IgG response (bottom) 

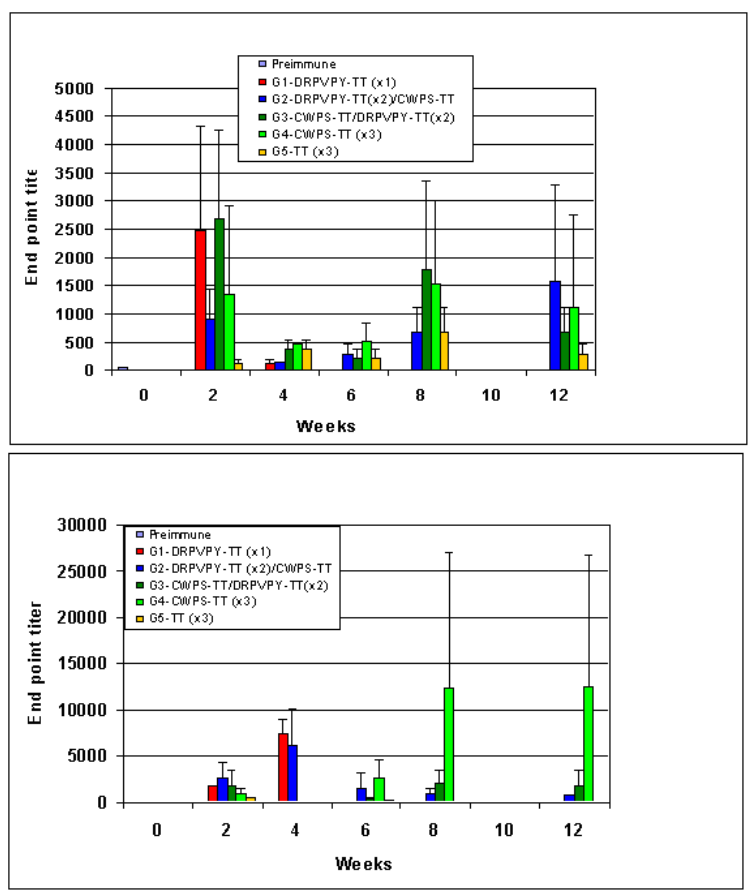

Fig. 6: Cross-reactivity in Experiment 2: Anti-peptide antibodies binding to heat-killed, pepsin treated Group A Streptococcus (GAS) bacteria as the solid-phase antigen in ELISA (see Materials and Methods). IgM response (top) and $\operatorname{IgG}$ response (bottom)

Inhibition ELISA studies with synthetic oligosaccharides corresponding to the CWPS (compounds 6-8, Fig. 3) as inhibitors of the binding of anti-peptide polyclonal antibodies to GAS bacteria, showed a maximum inhibitory activity of about $40 \%$, at a concentration of $250 \mu \mathrm{g} \mathrm{mL}$. There was no significant difference between the activities of the three inhibitors: branched trisaccharide, pentasaccharide and hexasaccharide (Fig. 7 III).

Finally, individual mouse sera from G1, experiment 2 (at week 5) were titrated against CWPSBSA-glycoconjugates, or BSA-peptide-conjugate as antigens (Fig. 8). The antisera from the four mice reacted best with the (hexasaccharide) 16 -sq-BSA (compound 13, Fig. 3), (hexasaccharide) 5 -BSA (compound 12, Fig. 3), pentasaccharide-BSA (compound 11, Fig. 3) and DRPVPY-BSA (compound 4, Fig. 2, data not shown); a weaker reaction, was observed with the CWPS-BSA (compound 9, Fig. 3) and branched-trisaccharide-BSA (compound 10, Fig. 3 ), with serum from mouse number 2 reacting the weakest (Fig. 8). These results corroborate the results above on the cross-reactivity observed with the polysaccharide and oligosaccharides.

Cross-reactivity: Anti-polysaccharide (GAS and CWPS) antibodies bind to DRPVPY-BSA: Mice immunized subcutaneously with heat-killed, pepsin treated GAS $\left(1 \times 10^{8}\right.$ bact. /mouse) at weeks 0 and 4 , responded with titers against DRPVPY-BSA.
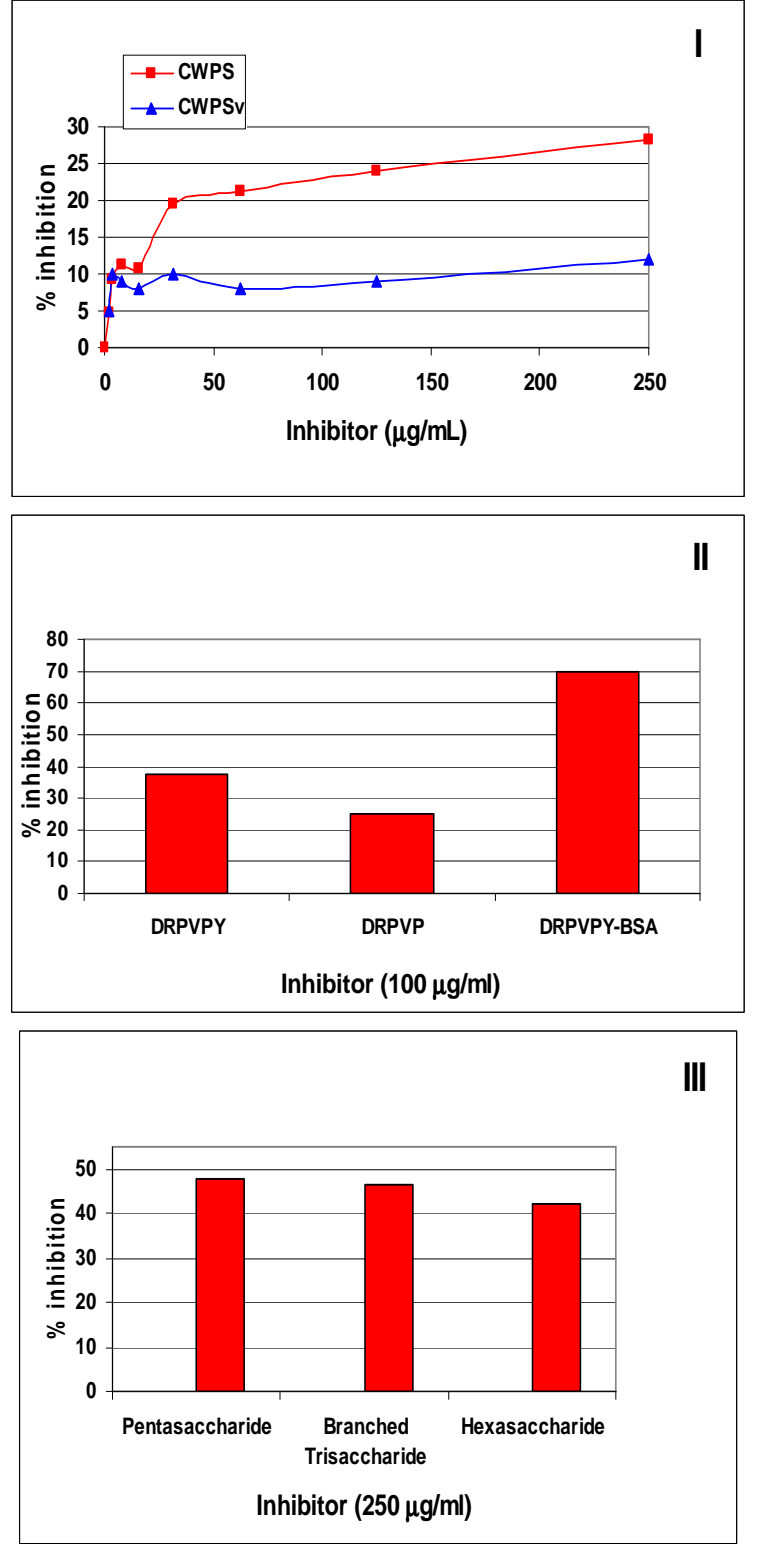

Fig. 7: Competitive inhibition ELISA using GAS bacteria as the solid-phase antigen and: (I) CWPS and CWPSv, (II) DRPVPY (compound 2, Fig. 1), DRPVP and DRPVPY-BSA (compound 4, Fig. 2) and (III), Synthetic oligosaccharides corresponding to CWPS (compounds 6-8, Fig. 3) as inhibitors

A high secondary IgG response was observed at week 6 (Fig. 9A). Mice primed with a low dose of CWPS-TT ( $1 \mu \mathrm{g} /$ mouse) responded with low titers to DRPVPYBSA, but with higher titers than those from control mice $(100 \mu \mathrm{g} /$ mouse TT, Fig. 9A). Mice immunized twice with CWPS-TT (2 $\mu \mathrm{g} /$ mouse, weeks 0 and 4) responded with IgG titers against DRPVPY-BSA after priming (weeks 2 and 4, Fig. 9B). However, no secondary response was seen after subsequent boosting (weeks 6 and 8, Fig. 9B). 


\section{DISCUSSION}

The major impact of this study is the demonstration of the carbohydrate cross-reactivity of the antisera elicited by immunization of mice with the synthetic peptide DRPVPY linked to protein-carrier, a peptide that mimics carbohydrate epitopes of the Streptococcus Group $\mathrm{A}^{[20]}$. Thus, the DRPVPY-TT conjugate ${ }^{[24]}$ when used in immunization of $\mathrm{BALB} / \mathrm{c}$ mice elicited antibodies whose specificity at different time points, as probed by ELISA, was also directed against oligosaccharide epitopes.

The immunogenicity of the DRPVPY-conjugates was evident from primary and secondary antibody responses (immunological memory) with high anti DRPVPY titers, which increased after booster immunizations (IgG) (Fig. 4 A-B). This result indicates that the conjugates effectively promoted a strong and rapid thymus-dependent response to DRPVPY.

Furthermore and more remarkably, the results demonstrate that the peptide DRPVPY can act as an immunogenic mimic when attached to a carrier-protein and can induce anti-carbohydrate antibodies. Titers against exposed polysaccharide on GAS bacteria were evident when a high dose of the peptide vaccine was administered to mice (Fig. 5-6). A lower dose of 20-40 $\mu \mathrm{g} /$ mouse did not elicit high cross-reactive titers (data not shown). These anti-GAS titers, despite the fact that they were much lower than those against peptide, were specific to carbohydrates. Antigenic cross-reactivities between the peptide and CWPS-epitopes were demonstrated by CWPS-specific inhibition of the antipeptide polyclonal antibodies binding to GAS bacteria with serum obtained after initial immunization (Fig. 7I). The role of the GlcNAc residue as the immunodominant sugar ${ }^{[12,31]}$ in the antibody response was evident since CWPSv, lacking the GlcNAc moiety, (compound 3, Fig. 1) was not able to inhibit the binding of the anti-peptide polyclonal to GAS (Fig. 7I). The fact that DRPVP was a poorer inhibitor than DRPVPY (Fig. 7II) may suggest a role of the tyrosine moiety in the antibody response; we had hypothesized previously that the VPY turn conformation might be necessary for effective immunogenicity ${ }^{[22,23]}$; experiments with antibodies of higher affinity will be essential for a critical test of this hypothesis. The multivalency effect was evident since the DRPVPY-BSA was able to cause up to $70 \%$ of inhibition while DRPVPY caused only about 35\% inhibition (Fig. 7II).

The presence of antibodies cross-reactive with carbohydrate was further demonstrated by the reactivity observed in the titration ELISA. Titers against all five antigens (compounds 9-13, Fig. 3) were observed (Fig. 8 ), although much lower than those against peptide (not shown). The sera reacted more weakly with the branched-trisaccharide conjugate and the strongest binding was with the pentasaccharide-BSA and (hexasaccharide) $)_{5}$-BSA.
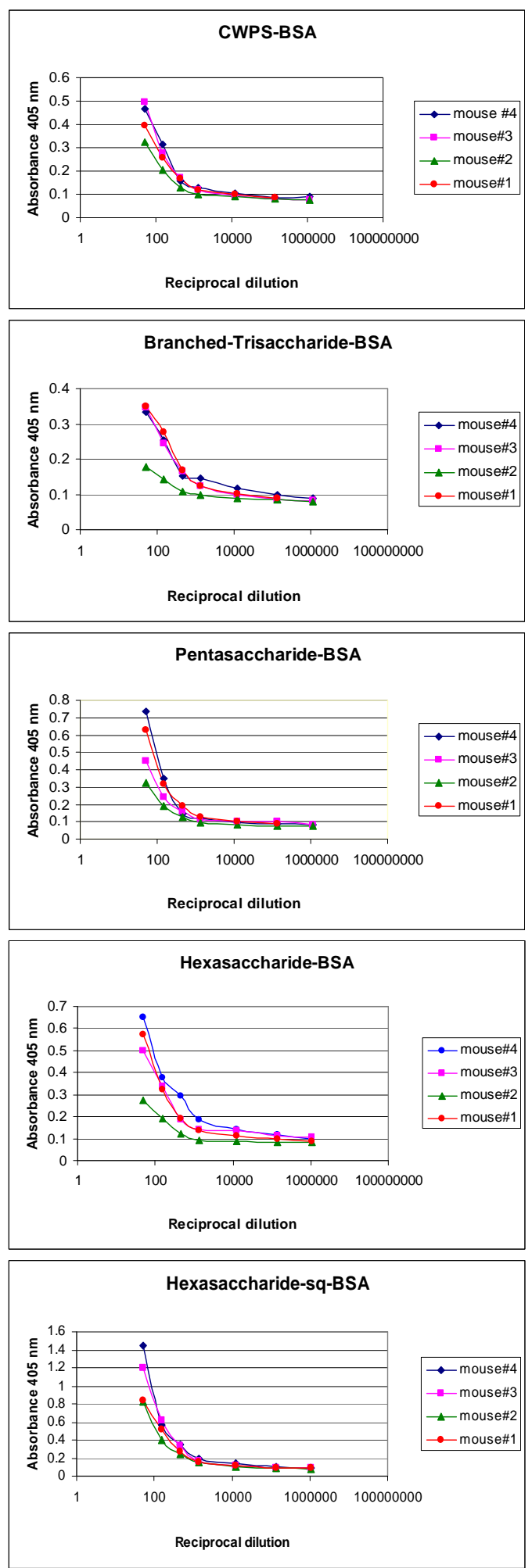

Fig. 8: Titration ELISA of anti-peptide polyclonal antibodies (IgG) using CWPS (compound 9, Fig. 3) and synthetic oligosaccharide-BSA conjugates (compounds 10-13, Fig. 3 ) as solid-phase antigens (see Materials and Methods)

Higher titers were observed with the (hexasaccharide) ${ }_{16}$-squarate-BSA conjugate, sharing the linker with the immunogen and having 16 
oligosaccharide units. This result indicates the dominance in the polyclonal specificity of an extended epitope, as observed earlier ${ }^{[12]}$. The specificity of the immune response for GAS oligosaccharides was corroborated by the inhibition observed with the branched-trisaccharide (compound 7, Fig. 3), pentasaccharide (compound 6, Fig. 3) and hexasaccharide (compound 8, Fig. 3), although no significant difference in inhibition among the inhibitors was observed (Fig. 7III).

The combined evidence leads us to conclude that (i) DRPVPY is an immunological mimic of CWPS, since high titers of cross-reactive antibodies were obtained by immunization of mice with DRPVPY-TT and (ii) the immune response is specific for the GAS oligosaccharide epitopes since the oligosaccharides and CWPS inhibit antibody binding to GAS.

However, a lack of secondary response (IgG) cross-reactive with GAS bacteria was observed after mice received a booster injection of DRPVPY-TT at equal dose (G1 experiment 1 and G2 experiment 2, respectively, in week 6-8, Fig. 5-6) or lower (G3 experiment 2, at week 12, Fig. 6). This lack of response may be the result of a carrier-induced suppression effect, which can decrease the production of antigenspecific antibodies ${ }^{[32]}$, so-called incomplete T-cell dependent ${ }^{[33]}$. While an increase in anti-DRPVPY titers after the booster injections was observed (Fig. 4A-G1 and 4B-G2, weeks 6-8), indicating the activation of DRPVPY-specific memory cells overall, we suggest that only a sub-population of these memory cells gives rise to carbohydrate cross-reactive antibodies that was not effectively activated. These results may arise from competition between populations of memory cells to peptide and carrier epitopes, the latter being better represented due to the relative sizes of the molecules. This effect has been noted in similar immunization strategies wherein the size and dose of the carrier molecule overwhelm that of the hapten of interest ${ }^{[34-37]}$.

Some strategies have been successful in minimizing the suppression effect. Thus, the change of carrier to a different protein, or use of smaller regions of the same carrier, or use of T-cell peptide epitopes have been shown to remove epitopes that activate the carrier-specific population of memory B-cells upon subsequent immunizations ${ }^{[34-38]}$. In our case, attempts to save the cross-reactive response were conducted in week 10 in both experiments. First, by changing the immunization carrier to BSA and boosting with a lower dose of DRPVPY-BSA were not successful (G1 experiment 1, week 12, Fig. 5). Alternatively, a balance in activation of hapten- and carrier-specific immune responses have been obtained through repeated immunization with different concentrations of the same immunoge ${ }^{[34]}$. In our hands, a booster injection with a 10-fold lower dose of DRPVPY-TT was tried in G3 experiment 2 , week 10 , or half dose (G3-experiment 1 , week 10); however, a secondary-like response (fast,
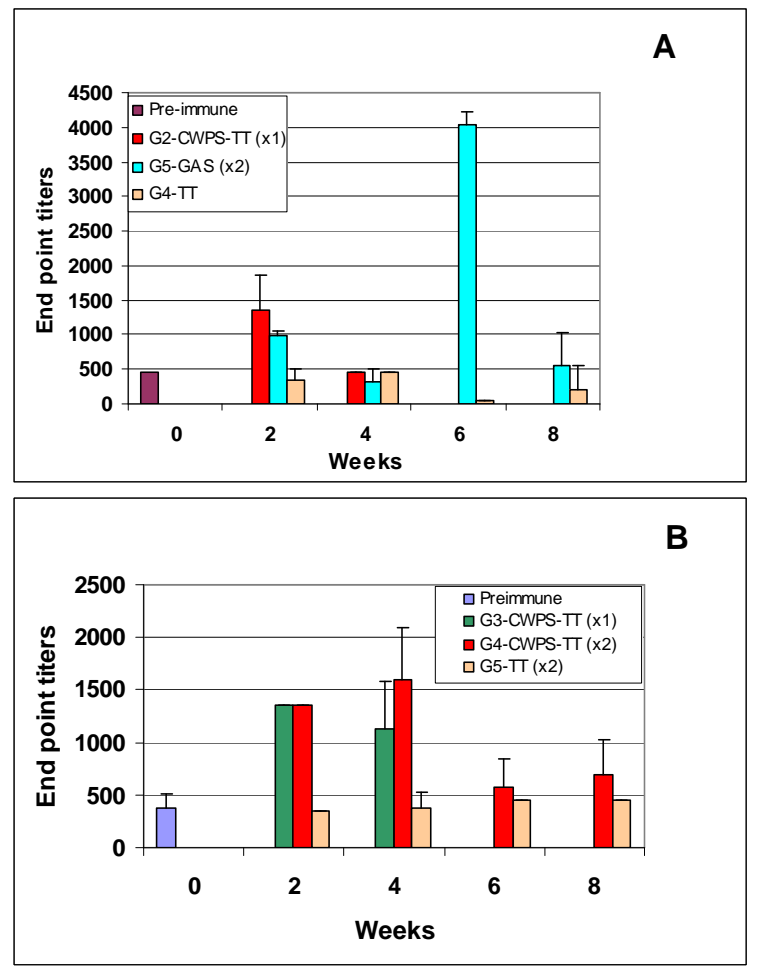

Fig. 9: Cross-reactivity. Anti-polysaccharide (GAS and CWPS-TT) antibodies (IgG) binding to DRPVPY-BSA (compound 4, Fig. 2) as the solid phase antigen; (A): Experiment 1; (B): Experiment 2

strong and high IgG titers) was not observed at week 12 (Fig. 6). In future work, the use of multiple antigen peptide (MAP) system, which directs a specific immune response to a localized concentration of peptide epitopes and avoids the use of carrier proteins ${ }^{[39]}$, or an universal 13 amino acid helper T-lymphocyte epitope AKXVAAWTLKAAA (Pan HLA-DR Epitope, PADRE), might present alternative strategies to solve this carrier effect ${ }^{[40-42]}$.

Mice vaccinated with heat-killed, pepsin treated GAS bacteria three times responded, as expected, with a delayed response due to the low density of antigenic determinants, with IgM titers dominating the primary response and higher $\operatorname{IgG}$ titers in the secondary responses (G5 experiment 1, Fig. 5). The booster effect was observed with repeated injections (G5 experiment 1, Fig. 5). Similarly, vaccination with low doses of the conjugate CWPS-TT (G4 experiment 2, Fig. 6) increased IgM titers after priming and subsequently IgG titers after the booster injections (G4 experiment 2, Fig. 6 ). It is also worth noting the differences in the mouse responses obtained after immunizations with the two experimental vaccines, DRPVPY-TT and CWPS-TT, indicative of their different immunogenicities. The DRPVPY-TT seemed able to induce a quicker and stronger primary response with higher $\mathrm{IgG}$ titers than the CWPS-TT, although a 50-fold higher dose/mouse was required, leading then to a carrier-suppression effect when a booster injection was given (Fig. 6). 
The CWPS-TT elicited an expected response for polysaccharide-protein conjugate vaccines ${ }^{[43]}$.

The existence of carbohydrate-peptide mimicry was further demonstrated by the increase in IgG titers to DRPVPY elicited by immunization with GAS (Fig. 9A). Immunization with CWPS-TT resulted in an increase in titers but no booster effect was observed (Fig. 9B). This behavior can be explained by a carriereffect, in which anti-TT antibodies overwhelm the antiCWPS antibodies cross-reactive with peptide, probably a very small population within the anti-CWPS antibodies.

It is relevant that one comment on the standard deviations. These are not unusually high for using 4 mice/group. The results can be compared to those in analogous studies. Thus, Beenhouwer et $a l^{[17]}$ have shown a similar distribution of anti-peptide titers as in the present study, although standard deviations were not shown and Fleuridor et al. ${ }^{[33]}$ and Maitta et al. ${ }^{[19]}$ obtained similar standard deviations for the anti-peptide titers, although with lower titer values. The higher standard deviation observed for the anti-carbohydrate titers derives from the fact that one mouse in each control group did not respond, the other mice giving very similar titers. Nevertheless, the overall conclusions of cross-reactivity are justified.

The facts (i) that repeated administration of the same DRPVPY-TT experimental vaccine (homologous boosting) did not lead to effective boosting of humoral responses, (ii) that DRPVPY is also an immunological mimic of CWPS and (iii) that both experimental vaccines DRPVPY-TT and CWPS-TT were available, led us to circumvent the problem by trying two heterologous boosting strategies ${ }^{[44]}$. This strategy has been successfully applied for carbohydrate peptide mimics and carbohydrates in the Cryptococcus neoformans system ${ }^{[17]}$.

The two strategies consisted of: (i) priming with DRPVPY-TT and boosting with CWPS-TT (G3 experiment 1-Fig. 5) or (ii) priming with CWPS-TT and boosting with DRPVPY-TT (G2 experiment 1-Fig. 5 and G3 experiment 2-Fig. 6). No titer increases against GAS were observed with the first strategy (Fig. 5-G3, week 6). With the second strategy, boosting with DRPVPY-TT at a high (Fig. 5-G2, week 6) and at a lower dose (Fig. 6-G3, week 10-12) or even using another carrier, BSA (Fig. 5-G2, week 10-12), although titers against GAS increased (Fig. 5-G2-week 8 and Fig.6-G3-week 8), did not have a response with the characteristics of a secondary response (fast, strong and high IgG titers). This behavior can be explained as a cross-reactive late primary response to the peptide, as supported by the increase in IgG titers to DRPVPY (Fig. 4A-G2 and Fig. 4B-G3) observed in weeks 6 and 8 , following boosting with DRPVPY-TT.

In conclusion, promising results from the study of the immunogenicity of a peptide-mimic of the Group A Streptococcus (GAS) cell-wall polysaccharide (CWPS) have been obtained. The primary response to the peptide immunogen had high titers of mature antibody isotype, $\mathrm{IgG}$, showing participation of both cellular and humoral immune responses. The antibodies generated were cross-reactive with carbohydrate epitopes displayed on GAS bacteria and this interaction was inhibited by CWPS and oligosaccharide fragments thereof, showing conclusively that the peptide DRPVPY is an antigenic mimic of the GAS CWPS. Conversely, immunization with GAS displaying CWPS led to a cross-reactive response against DRPVPY. However, a long term, stable response against GAS, could not be maintained for groups immunized with DRPVPY-TT due to the carrier-suppression-effect. Further investigation of the effects resulting from boosting with different peptide-conjugates will likely be required for the design of effective anti-GAS vaccines based on mimetic-peptides.

Survival and challenge studies will be conducted when an appropriate vaccine formulation is defined, that is, one with a response that can be reliably boosted. The present study was intended to serve as a prelude to define the parameters; the results obtained are of importance because they do show reliably that peptidecarbohydrate cross-reactivity exists upon immunization.

\section{ACKNOWLEDGEMENT}

This work was supported by a grant from the Natural Sciences and Engineering Research Council of Canada.

\section{REFERENCES}

1. Cunningham, M.D., 2000. Pathogenesis of group a streptococcal infections Clin. Microbiol. Rev., 13: 470-511.

2. Stevens, D.L., 1997. The toxins of Group A Streptococcus, the flesh eating bacteria. Immunolog. Invest., 26: 129-150.

3. Stevens, D.L., 2003. Skin and soft tissue infections. Infect. Med., 20: 483-+.

4. Bisno, A.L., 1985. In Principles and Practice of Infectious Diseases. Mandell, G.L., R.G. Douglas and J.E. Bennet, Eds. Wiley: New York.

5. Quinn, R.W., 1989. Comprehensive review or morbidity and mortality trends for rheumatic fever, strptococcal disease and scarlet fever: The decline of rheumatic fever. Rev. Infect. Dis., II: 928-952.

6. Stevens, D.L., M.H. Tanner, J. Winship, R. Swarts, K.M. Ries, P.M. Schlievert and E. Kaplan, 1989. Severe group A streptococcal infections associated with a toxic shock-like syndrome and scarlet fever toxin. A.N. Engl. J. Med., 321: 1-7.

7. Stollerman, G.H., 1988. Changing group A streptococci: The reappearance of streptococcal toxic shock. Arch. Intern. Med., 148: 1268-1270. 
8. Kehoe, M.A., 1991. Group A streptococcal antigens and vaccine potential. Vaccine, 9: 797806.

9. Hall, M.A., S.D. Stroop, M.C. Hu, M.A. Walls, M.A. Reddish, D.S. Burt, G.H. Lowell and J.B. Dale, 2004. Intranasal immunization with multivalent group a streptococcal vaccines protects mice against intranasal challenge infections. Infect. Immun., 72: 2507-2512.

10. Hu, M.C., M.A. Walls, S.D. Stroop, M.A. Reddish, B. Beall and J.B. Dale, 2002. Immunogenicity of a 26-valent group a streptoccocal vaccine. Infect. Immun., 70: 2171-2177.

11. Kotloff, K.L., M. Corretti, K. Palmer, J.D. Campbell, M.A. Reddish, M.C. Hu, S.S. Wasserman and J.B. Dale, 2004. Safety and immunogenicity of a recombinant multivalent group a streptococcal vaccine in healthy adults. JAMA, 292: 709-715.

12. Michon, F., S.L. Moore, J. Kim, M.S. Blake, F.-I. Auzanneau, B.D. Johnston, M.A. Johnson and B.M. Pinto, 2005. The doubly-branched hexasaccharide epitope on the cell-wall polysaccharide of Group A Streptococcus. recognized by human and rabbit antisera Infect. Immun., 73: 6383-6389.

13. Sabharwal, H., F. Michon, D. Nelson, W. Dong, K. Fuchs, R. Carreno-Manjarrez, A. Sarkar, C. Uitz, A. Viteri-Jackson, R.S. Rodriguez-Suarez, M.S. Blake and J.B. Zabriskie, 2006. Group A Streptococcus (GAS) Carbohydrate as an Immunogen for Protection against GAS Infection J. Infect. Dis., 193: 129-135.

14. Ji, Y., B. Carlson, A. Kondagunta and P.P. Clearly, 1997. Intranasal Immunization with C5a Peptidase Prevents Nasopharyngeal Colonization of Mice by the Group A Streptococcus. Infect. Immun., 65: 2080-2087.

15. Johnson, M.A. andB.M. Pinto, 2002. Molecular mimicry of carbohydrates by peptides Aust. J. Chem., 55: 13-25.

16. Roy, R., 2004. New trends in carbohydrate-based vaccines. Drug Discovery Today: Technologies, 1: 327-336.

17. Beenhouwer, D.O., R.J. May, P. Valadon and M.D. Scharff, 2002. High affinity mimotope of the polysaccharide capsule of Cryptococcus neoformans identified from an evolutionary phage peptide library. J. Immunol., 169: 6992-6999.

18. Cunto-Amesty, G., P. Luo, B. Monzavi-Karbassi, A. Lees, J. Alexander, M.F. Del Guercio, M.H. Nahm, C. Artaud, J. Stanley and T. KieberEmmons, 2003. Peptide mimotopes as prototypic templates of broad-spectrum surrogates of carbohydrate antigens Cell. Mol. Biol., 49: 245-254.
19. Maitta, R.W., K. Datta, A. Lees, S.S. Belouski and L.A. Pirofski, 2004. Immunogenicity and efficacy of Cryptococcus neoformans capsular polysaccharide glucuronoxylomannan peptide mimotope-protein conjugates in human immunoglobulin transgenic mice Infect. Immun., 72: 196-208.

20. Harris, S.L., L. Craig, J.S. Mehroke, M. Rashed, M.B. Zwick, K. Kenar, E.J. Toone, N. Greenspan, F.I. Auzanneau, J.R. MarinoAlbernas, B.M. Pinto and J.K. Scott, 1997. Exploring the basis of peptide-carbohydrate crossreactivity: Evidence for discrimination by peptides between closely related anti-carbohydrate antibodies. Proc. Natl. Acad. Sci. U.S.A., 94: 2454-2459.

21. Reimer, K.B., M.A.J. Gidney, D.R. Bundle and B.M. Pinto, 1992. Immunochemical characterization of polyclonal and monoclonal streptococcus group-a antibodies by chemically defined glycoconjugates and synthetic oligosaccharides. Carbohydr. Res., 232: 131-142.

22. Johnson, M.A., A. Rotondo and B.M. Pinto, 2002. NMR studies of the antibody-bound conformation of a carbohydrate-mimetic peptide. Biochemistry, 41: 2149-2157.

23. Johnson, M.A. andB.M. Pinto, 2004. NMR spectroscopic and molecular modeling studies of protein-carbohydrate and protein-peptide interactions. Carbohydr. Res., 339: 907-928.

24. Hossany, R.B., M.A. Johnson, A.A. Eniade and B.M. Pinto, 2004. Synthesis and immunochemical characterization of protein conjugates of carbohydrate and carbohydrate-mimetic peptides as experimental vaccines Bioorg. Med. Chem., 12: 3743-3754.

25. Krause, R.M., 1970. The search for antibodies with molecular uniformity Adv. Immunol., 12.

26. Pitner, J.B., W.F. Beyer, T.M. Venetta, C. Nycz, M.J. Mitchell, S.L. Harris, J.R. Marino-Albernas, F.I. Auzanneau, F. Forooghian and B.M. Pinto, 2000. Bivalency and epitope specificity of a highaffinity IgG3 monoclonal antibody to the Streptococcus Group A carbohydrate antigen. Molecular modeling of a Fv fragment. Carbohydrate Res., 324: 17-29.

27. Auzanneau, F.I., F. Forooghian and B.M. Pinto, 1996. Efficient, convergent syntheses of oligosaccharide allyl glycosides corresponding to the Streptococcus Group A cell-wall polysaccharide. Carbohydr. Res., 291: 21-41.

28. Hoog, C., A. Rotondo, B.D. Johnston and B.M. Pinto, 2002. Synthesis and conformational analysis of a pentasaccharide corresponding to the cell-wall polysaccharide of the Group A Streptococcus. Carbohydr. Res., 337: 2023-2036. 
29. Auzanneau, F.I. andB.M. Pinto, 1996. Preparation of antigens and immunoadsorbents corresponding to the Streptococcus Group A cell-wall polysaccharide Bioorg. Med. Chem., 4: 2003-2010.

30. Zou, W., S. Borrelli, M. Gilbert, T. Liu, R.A. Pon and H.J. Jennings, 2004. Bioengineering of surface GD3 ganglioside for immunotargeting human melanoma cells. J. Biol. Chem., 279: 25390-25399.

31. Malkiel, S., L. Liao, M.W. Cunningham and B. Diamond, 2000. T-cell-dependent antibody response to the dominant epitope of Streptococcal polysaccharide, N-acetyl-glucosamine, is crossreactive with cardiac myosin. Infect. Immun., 68: 5803-5808.

32. Peeters, C.A.M., A.J. Tenbergen-Meekes, J.T. Poolman, M. Beurret, B.J.J. Zegers and G.T. Rijkers, 1991. Effect of carrier priming on immunogenicity of saccharide-protein conjugate vaccines. Infect. Immun., 59: 3504.

33. Fleuridor, R., A. Lees and L.A. Pirofski, 2001. A cryptococcal capsular polysaccharide mimotope prolongs the survival of mice with Cryptococcus neoformans infection. J. Immunol., 166: 10871096.

34. Herzenberg, L.A., T. Tokuhisa and K. Hayakawa, 1983. Epitope-specific regulation. Ann. Rev. Immunol., 1: 609-632.

35. Herzenberg, L.A. and T. Tokuhisa, 1980. Carrierpriming leads to hapten-specific suppression. Nature, 285: 664-667.

36. Putz, M.M., W. Ammerlaan, F. Schneider, G. Jung and C.P. Muller, 2004. Humoral immune responses to a protective peptide-conjugate against measles after different prime-boost regimens. Vaccine, 22: 4173-4182.

37. Schutze, M.P., E. Deriaud, G. Przewlocki and C. Leclerc, 1989. Carrier-induced epitopic suppression is initiated through clonal dominance. J. Immunol., 142: 2635-2640.
38. Schutze, M.P., C. Leclerc, M. Jolivet, F. Audibert and L. Chedid, 1985. Carrier-induced epitopic suppression, a major issue for future synthetic vaccines. J. Immunol., 135: 2319-2322.

39. Monzavi-Karbassi, B., S. Shamloo, M. KieberEmmons, F. Jousheghany, P. Luo, K.Y. Lin, G. Cunto-Amesty, D.B. Weiner and T. KieberEmmons, 2003. Priming characteristics of peptide mimotopes of carbohydrate antigens. Vaccine, 21: 753-760.

40. Alexander, J., M.F. del Guercio, A. Maewal, L. Qiao, J. Fikes, R. Chesnut, J. Paulson, D. Bundle, S. DeFrees and A. Sette, 2000. Linear PADRE T helper epitope and carbohydrate $\mathrm{B}$ cell epitope conjugates induce specific high titer IgG antibody responses. J. Immunol., 14: A1131-A1131.

41. Alexander, J., M.F. del Guercio, B. Frame, A. Maewal, A. Sette, M.H. Nahm and M.J. Newman, 2004. Development of experimental carbohydrateconjugate vaccines composed of Streptococcus pneumoniae capsular polysaccharides and the universal helper T-lymphocyte epitope (PADRE $((\mathrm{R})))$. Vaccine, 22: 2362-2367.

42. Alexander, J., M.F. del Guercio, B. Frame, A. Maewal, A. Sette, G. Newman and M. Newman, 2001. Pneumococcal conjugate vaccines comprised of PADRE $\mathrm{T}$ helper epitope and capcular polysaccharides induce specific high titer $\operatorname{IgG}$ antibody responses. Faseb J., 15: A1189-A1189.

43. Lindberg, A.A., 1999. Glycoprotein conjugate vaccines, Vaccine, 17: S28-S36.

44. Woodland, D.L., 2004. Jump-starting the immune system: Prime-boosting comes of age. Trends Immunol., 25: 98-104. 